\title{
Role of Nasal Endoscopy in Initial Management of Epistaxis.
}

\author{
Irfan ul Shamas ${ }^{1}$
}

\begin{abstract}
:
Aim: To compare the precision,efficacy and complication of nasal endoscopic assisted management of epistaxis with headlight assisted nasal packing. Materials and Methods: Two groups of twenty patients each were placed randomly in Group A and Group B. Patients in Group A were managed with headlight assisted nasal packing and Group B patients were managed with nasal endoscopic assisted control of epistaxis. Results: Exact site of bleeding was located in $90 \%$ patients of Group B. All patients in Group A complained of dry mouth $(100 \%)$, halitosis in $6(30 \%)$ patients, $12(60 \%)$ patients had headache and discomfort,7(35\%) patients had epiphora. There was no complication in Group B. Conclusions: Epistaxis is a common ENT emergency and routine blind hasty nasal packs should be avoided. Nasal endoscopes should be routinely used to identify site of bleeding and cauterisation of the targeted area should be done gently with least collateral damage to healthy mucosa. Good and easy control with less complications and no admissions are all possible with the wonder tool called " nasal endoscope".
\end{abstract}

Keywords : Epistaxis, nasal endoscopy, nasal packing.

International Journal of Human and Health Sciences Vol. 03 No. 03 July'19 Page : 158-161 DOI: http://dx.doi.org/10.31344/ijhhs.v3i3.94

\section{Introduction}

There has been a paradigm shift in the management of epistaxis over the last 30 years ever since Budrovich and Saette ${ }^{1}$ in 1992 did the first nasal endoscopic procedure to control epistaxis. The main reason for this paradigm shift was the advent of nasal endoscopy. Treatment of epistaxis used to primarily revolve around blind headlight assisted cauterization and nasal packing.Ligature of the external carotid artery conducted by $\mathrm{Hyde}^{2}$ in 1935 was the first vascular procedure for epistaxis control.Chandler ${ }^{3}$, in 1965 was the first to perform a ligature of the maxillary artery transantrally in an attempt to intervene next to an intranasal bleeding site. Intranasal approaches for epistaxis control were established after the first ligature of the sphenopalatine artery using a microscope (Stamm, 1985) ${ }^{4}$ and an endoscope (Budrovich and Saette, 1992) ${ }^{1}$. Since then endoscope has become a popular tool for management of epistaxis.

Epistaxis is alarming both for the patient and treating emergency physician and inadvertently leads to hurriedly done blind nasal packing. Blind nasal packing can convert a single bleeding spot into a large abraded bleeding mucosa. Sometimes packing may not reach the targeted spot leading to ineffective bleeding control. Use of nasal endoscope for management of epistaxis is accurate and effective. The aim of this study is to compare the nasal endoscope as a tool in control of epistaxis when used primarily with blind nasal packing.

\section{Materials And Methods}

Two groups of 20 patients each from age group of 16 years and above were included in this study from September 2018 to December 2018. The study was done in District Hospital Pulwama,a secondary level hospital catering to the population of South Kashmir. Patients in Group A underwent a headlight assisted nasal packing which was kept in situ for 48 hours. Patients in Group B underwent a primary diagnostic nasal endoscopy and site of bleeding was looked for. When the site was identified it was cauterised by $50 \%$ tricloroacetic acid or Bipolar Diathermy under topical 10\% Lignocaine spray. All patients were followed up for three weeks at weekly intervals. All the patients were screened for any coagulopathies and systemic disorders like Diabeties Mellitus and Hypertension.

1. Dr.Irfan UL Shamas: Consultant ENT JK Health Services India

Correspondence to: Dr.Irfan UL Shamas, Consultant ENT JK Health Services India, E-mail: drirfan007@gmail.com 


\section{Results}

All the patients of Group A had complaints of dry mouth ( $100 \%$ ), wheras none of the patients in Group B complained of dryness of mouth. 6 patients (30\%) of Group A complained of halitosis wheras none of the patients in Group B complained of Halitosis. $12(60 \%)$ patients of Group A complained of Headache and Discomfort whereas 2 patients $(10 \%)$ complained of discomfort and headache in Group B. Epiphora after nasal packing was observed in $7(35 \%)$ patients whereas no patient in Group B complained of Epiphora.

Nasal pack was removed after 48 hours. 6 patients $(30 \%)$ of Group A had rebleeding which was controlled endoscopically with no rebleeding. Nasal endoscopy after pack removal revealed nasal mucosal abrasions in $11(55 \%)$ patients which was treated by local Neosporin ointment(Bacitracin) and decongestant drops. Two $(10 \%)$ patients in Group B bleeded again and were treated with revision endoscopic assisted cauterisation. None of the patients of both groups had any septal perforation at one month of post treatment period. Two patients (10\%) of Group A developed Synaechiae which were released endoscopically. No patient of Group B developed synaechiae.

No attempt was made to identify site of bleeding in Group A primarily. In Group B exact site of bleeding was identified in $18(90 \%)$ patients. $13(65 \%)$ patients had septum as site of bleeding whereas $7(35 \%)$ patients had lateral wall as source of bleeding. Anterior septum(n=8) was the most common site of septal group and middle turbinate was the most common site of bleeding in lateral wall group.

\section{Discussion}

Epistaxis can be idiopathic(no cause) or secondary( trauma, surgery, anti coagulants, Hypertension). It can be anterior or posterior. Its called anterior when the source is anterior to the plane of pyriform aperture. The site of anterior epistaxis is usually KIesselback's plexus. Posterior epistaxis is from vessels originating posterior to pyriform aperture. These are commonly diffuse and troublesome. The most common site of posterior epistaxis is lateral wall, floor of nose or Woodruff's plexus.

Management of epistaxis is multidimentional. Control of nasal bleed promptly with treatment of any concomitant systemic disease should be done simultaneously. Direct management includes endoscopic visualisation of bleeding source and cauterisation. Indirect means include nasal packing and medical treatment. If both fail
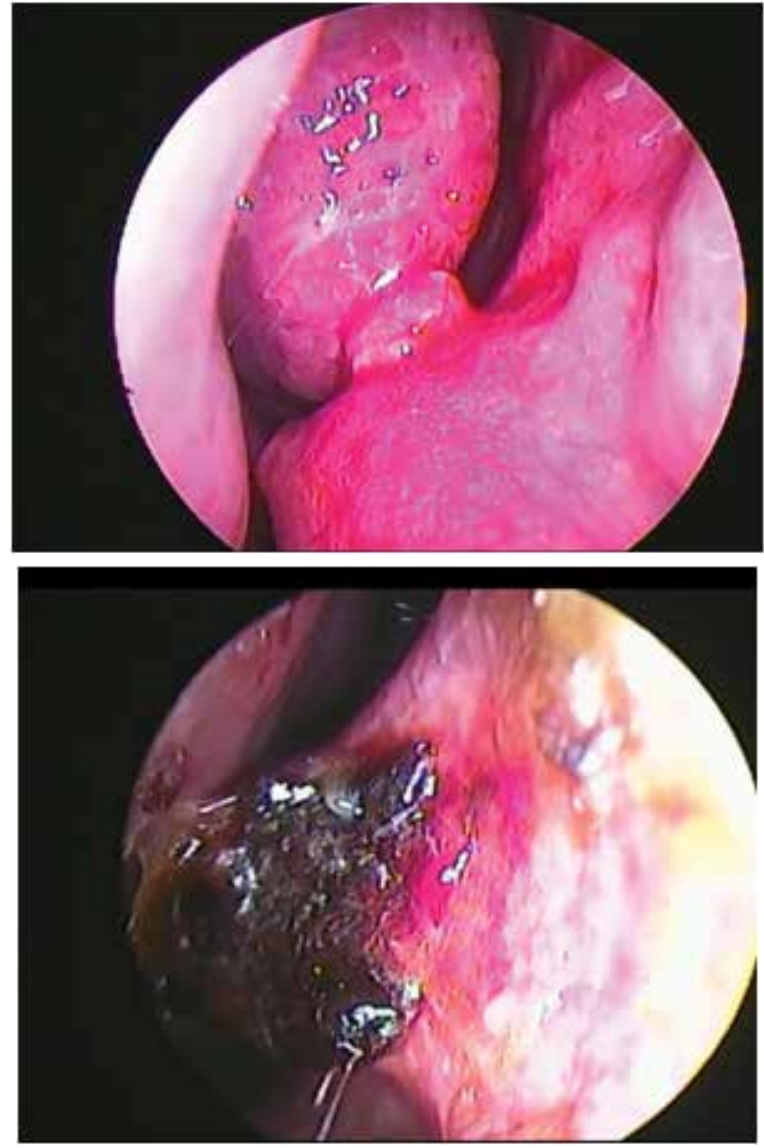

Figure 1 . Septal pappiloma as site of bleeding. Figure 2. Septal acute deviation with big septal ulcer as site of bleeding
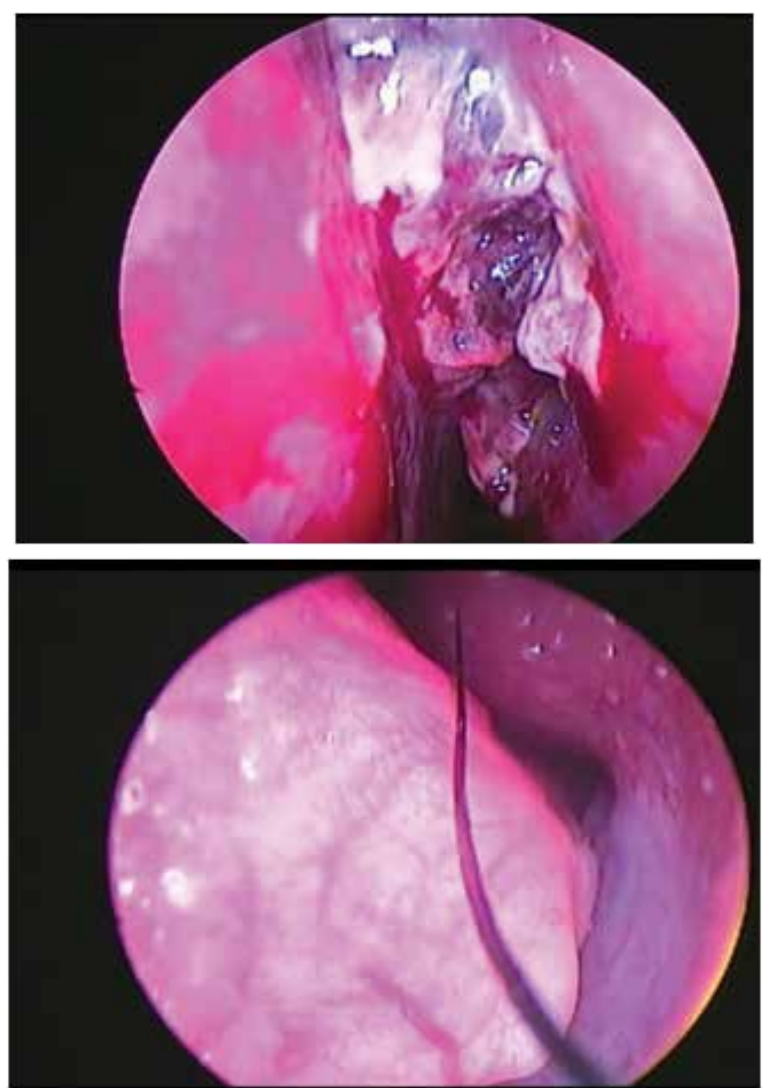

Figure 3. Middle turbinate mass as source of bleeding Figure 4. Septal Telangiectasia of vein in Littles area. 

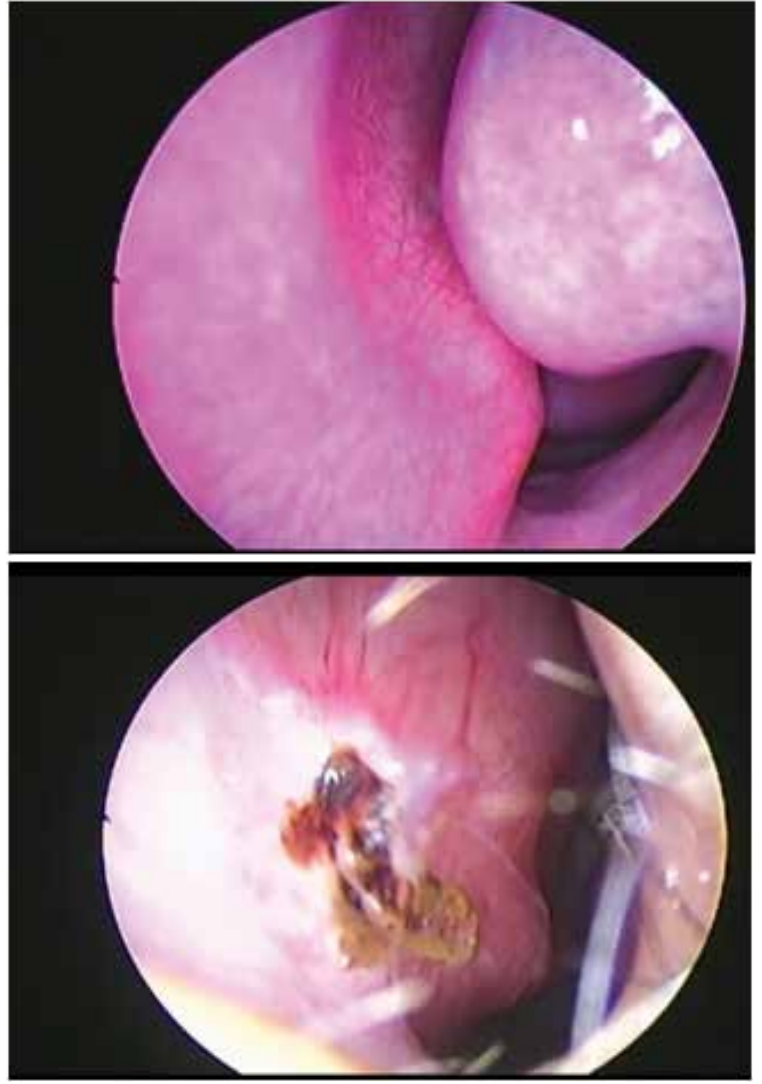

Figure 5. Diffuse Telangiectasia of small veins Figure 6. Post TCA cautery of ulcer on Littles area of septum.

surgical intervention can be done which includes ligation of different vessels and embolisations.

As endoscopes are readily available, it is advisable to use them for primary control of epistaxis. Endoscopic control of bleeding can be done by tricloroacetic acid, silver nitrate, bipolar cautery, monopolar cautery, coblation or carbon dioxide laser. When done gently there is minimal trauma to healthy mucosa and less colateral injury to surrounding areas. It is done circumferentialy from periphery to the centre without causing damage to adjacent mucosa. Biploar cautery is preferred over monopolar diathermy as there are chances of blindness by current propogation with monopolar cautery 5 . Endoscopy identifies source of bleeding in $80 \%$ cases $^{6}$. Woodruff's area may be missed by blind nasal packing and can be a source of pack failure or rebleeding. This area can be easily tackled by a nasal endoscope. Control of epistaxis by immediate use of nasal endoscope is reported in $90 \%$ cases $^{7}$. Endoscopic immediate management of epistaxis also decreases in patient admission of patients and leads to less admissions ${ }^{7}$. Regular use of clinical endoscopy during the last decade amplified the knowledge on the etiology and treatment of epistaxis. The bleeding source inside the nasal cavity could be more easily and accurately identified. Moreover, other less invasive procedures, such as cauterization of the bleeding source, could be done presenting high efficacy rates ${ }^{7}$. Local cauterization of the bleeding spot, which was previously limited to anterior portions of the nasal cavity, could be amplified to posterior regions, with the advent of endoscopic visualization.

Blind nasal packing has many complications. It can create more raw areas in nose, synaechiae formation,blockage of NLD leading to epiphora, blockage of sinus ostia leading to sinusitis and headache, blockage of ET opening leading to otitis media, sleep disturbance, facial pressure and numbness, septal perforation. In this study all complications associated with nasal packing enumerated above were noticed except septal perforation. There was no complication seen in patients with endoscopic management of epistaxis. Therefore, we should avoid hasty blind nasal packs and endoscopic management should be done whenever possible.

\section{Conclusion}

Epistaxis is a common ENT emergency and routine blind hasty nasal packs should be avoided. Nasal endoscopes should be routinely used to identify site of bleeding and cauterisation of the targeted area should be done gently with least collateral damage to healthy mucosa. Good and easy control with less complications and no admissions are all possible with the wonder tool called " nasal endoscope". 
International Journal of Human and Health Sciences Vol. 03 No. 03 July'19

\section{References:}

1. Budrovich R, Saetti R. Microscopic and endoscopic ligature of the sphenopalatine artery. Laryngoscope 1992; 102: 1391-1394.

2. Hyde FT. Ligation of the external carotid artery for control of idiopathic nasal haemorrage. Laryngoscope 1925; $35: 899$.

3. Chandler JR, Serrin AJ. Transantral ligation of the maxillary artery for epistaxis. Laryngoscope 1965; 75: 1151-1159.

4. Stamm AC, Pinto JA, Neto AF et al. Microsurgery in severe posterior epistaxis. Rhinology 1985; 23: 321-325.

5. Vanden Abeele $\mathrm{D}$, et al. Blindness due to electrocoagulation following functional endoscopic sinus surgery. J Laryngol Otol. 1996 Mar;110(3):261-264.

6. Wurman LH, Sack JG, Flannery JV, Paulson TO. Selective endoscopic electrocautery for posterior epistaxis. Laryngoscope. 1988;98:1348-1349.
7. O’Donnell M, Robertson G, McGarry GW.A new bipolar diathermy probe for the outpatient management of adult acute epistaxis.Clin Otolaryngol Allied Sci. 1999 Dec;24(6):537-541.

8. Sunita Chapoola et al. Comparison of blind nasal packing vs endoscopic control of epistaxisin an emergency setting. International Journal of Head and Neck Surgery, May-August2011;2(2):79-82.

9. Glauco Soares de Almeida et al.Nasal endoscopy and localization of the bleeding source in epistaxis: last decade's revolution.Braz J Otorhinolaryngol. 2005 Mar- Apr;71(2):146-148.

10. Babin $\mathrm{E}$ et al. Anatomic variations of the arteries of the nasal fossa. Otol Head Neck Surg 2003; 128 (2): 236-239.

11. Batra $P$ et al. Surgical anatomy of the distal maxillary artery. Otol Head Neck Surg 2004; 131 (2): 186-187. 